https://helda.helsinki.fi

\title{
Expectations of patients with colorectal cancer towards nursing care- a thematic analysis
}

\section{Tuominen, Leena}

2020-02

Tuominen , L , Leino-Kilpi , H \& Meretoja , R 2020 , ' Expectations of patients with colorectal cancer towards nursing care- a thematic analysis ' , European Journal of Oncology Nursing , vol. 44 , 101699 . https://doi.org/10.1016/j.ejon.2019.101699

http://hdl.handle.net/10138/322514

https://doi.org/10.1016/j.ejon.2019.101699

publishedVersion

Downloaded from Helda, University of Helsinki institutional repository.

This is an electronic reprint of the original article.

This reprint may differ from the original in pagination and typographic detail.

Please cite the original version. 


\title{
Expectations of patients with colorectal cancer towards nursing care- a thematic analysis
}

\author{
Leena Tuominen $^{\mathrm{a}, \mathrm{b}, *}$, Helena Leino-Kilpi ${ }^{\mathrm{b}, \mathrm{c}}$, Riitta Meretoja ${ }^{\mathrm{b}, \mathrm{d}}$ \\ ${ }^{a}$ Comprehensive Cancer Center, Helsinki University Hospital, Haartmaninkatu 4, PL 180, 00029, Helsinki, Finland \\ ${ }^{\mathrm{b}}$ Department of Nursing Science, University of Turku, Joukahaisenkatu 3-5, 20014, Turku, Finland \\ ${ }^{\mathrm{c}}$ Turku University Hospital, Kiinamyllynkatu 4-8, 20521, Turku, Finland \\ ${ }^{\mathrm{d}}$ Helsinki University Hospital, Stenbäckinkatu 9, PL 100, 00029, Helsinki, Finland
}

\section{A R T I C L E I N F O}

\section{Keywords:}

Expectations

Nursing care

Patients with colorectal cancer

Thematic analysis

\begin{abstract}
A B S T R A C T
Purpose: The purpose of this study was to explore comprehensively expectations of patients with colorectal cancer towards nursing care in the chemotherapy context.

Methods: A purposive sample of patients with colorectal cancer $(\mathrm{n}=15)$ was interviewed individually at the outpatient clinic in one university hospital chemotherapy unit. The data were analysed with thematic analysis. Results: Three main themes were identified in the data. Firstly, patients expected to be empowered with knowledge of disease process, side effects and their self-management and peer support. Secondly, patients expected to be humanely encountered, which included being encountered with support, compassion and hope. Thirdly, patients expected to be skillfully cared for with systematic assessment, expertise, continuity and advocacy.

Conclusions: Besides reliable knowledge of cancer treatment and care, patients expected the sympathetic presence of a nurse whose professional skills they can trust. The results may be utilised in intervention development by focusing on themes significant to these patients. The results may help nurses to enhance person-centred care as well as to encounter patients according to their expectations.
\end{abstract}

\section{Introduction}

Annually, about 1.8 million people are affected with colorectal cancer (CRC), the third most commonly diagnosed cancer $(10.2 \%$ of the total cases) among both sexes globally (Bray et al., 2018). As the number of patients affected with CRC is growing, more people will need support to manage their lives with the illness. When diagnosed with cancer, patients receive tailored medical care, but less is known of whether nursing care is planned according to patients' expectations.

There are only few studies of the expectations of patients with cancer towards their care (Ryhänen et al., 2012; Simacek et al., 2007; Tombal et al., 2013; Vaartio-Rajalin et al., 2015) despite the ongoing emphasis of improving patient experience in health care. Expectations towards the nursing care vary according to the phase of care (VaartioRajalin et al., 2015), personality, age and level of symptom distress (Shun et al., 2014). In addition, patients' needs are different related to particularity (Almyroudi et al., 2011; Pardon et al., 2009; Ryhänen et al., 2012; Simacek et al., 2007) and clarity of information; for example, patients may not be aware of receiving palliative instead of curative care (Tombal et al., 2013). A study by Kotronoulas et al.
(2017) revealed 136 individual needs of patients with colorectal cancer, of which $51 \%$ concerned information/education or communication issues. The need for emotional support was related to fear of recurrence. Beaver et al. (2010) showed that patients' expectations after bowel surgery related to the continuity of care and tailored information during the follow-up phase (Beaver et al., 2010). When care is person-centred, it takes into account people's preferences and expressed needs (Health Innovation Network, 2016). As a result, patients' voice is strengthened, and patient outcomes, such as satisfaction (Morgan and Yoder, 2012) and quality of care are improved. Moreover, care that meets patients' expectations reduces pressure on health and social services (Health Innovation Network, 2016).

Knowledge expectations are prevalent among patients with cancer. Patients expect to receive knowledge of care alternatives and their effect, the treatment process and one's own situation as well as explanation of the care plan (Vaartio-Rajalin et al., 2015). Knowledge expectations regarding treatment side effects have been studied extensively. Patients expect knowledge of the impact of treatment on daily life (Simacek et al., 2007; Tombal et al., 2013), health in the long term (Goossens et al., 2014; Halkett et al., 2012) and side effects' self-

\footnotetext{
* Corresponding author. Comprehensive Cancer Center, Helsinki University Hospital, Haartmaninkatu 4, PL 180, 00029, Helsinki, Finland.

E-mail addresses: leetuo@utu.fi (L. Tuominen), helena.leino-kilpi@utu.fi (H. Leino-Kilpi), riitta.meretoja@hus.fi (R. Meretoja).
} 
management (Roberts et al., 2008; Simacek et al., 2007; Tombal et al., 2013; van Weert et al., 2013). Some patients expect knowledge about treatment's impact on sexuality and fertility (Goossens et al., 2014; Rasmusson et al., 2013) and the lifestyle factors related to recurrence (Roberts et al., 2008). Few studies have reported patients' knowledge expectations regarding recent developments in cancer diagnostics and treatments (Roberts et al., 2008) or economic support (Vaartio-Rajalin et al., 2015).

Knowledge expectations during the care process seem to vary over time. Closer to diagnosis, patients expect to have knowledge and respect for their emotional state (Ryhänen et al., 2012; Thorne et al., 2014). At the beginning of chemotherapy (CT), knowledge expectations relate to disease and its treatment (Ryhänen et al., 2012). At the end of treatment, patients expect clarification of follow-up and support in adapting to normal life (Thorne et al., 2014). Expectations of patients suffering from advanced cancer are related to knowledge of disease prognosis and life expectancy (Pardon et al., 2009; Simacek et al., 2007; van Weert et al., 2013), end-of-life decisions and possibilities for palliative care (Pardon et al., 2009). Patients value direct communication balanced with honesty and hope (Thorne et al., 2014). In the case of recurrence, patients expect support with optimism, caring and compassion. Patients' expectations of curative treatment and normal life appear to persist during the illness trajectory irrespective of cancer type or severity (Simacek et al., 2007; Tombal et al., 2013) demonstrating the importance of hope.

Patients' preferences in decision-making have been widely studied with varying results. Some patients appreciate shared decision-making (Thorne et al., 2014), whereas others prefer a collaborative approach or leave decisions entirely to their doctor (Almyroudi et al., 2011; Kvåle and Bondevik, 2008; Tombal et al., 2013). Patients wish to make decisions on treatment $(14.8 \%)$, transfer $(25.0 \%)$ and end-of-life care (49.2\%), but not medical decisions in general (9.3\%) (Pardon et al., 2009).

According to some earlier studies, expectations for psychological support may not be as prevalent as presumed among patients with cancer. In the UK, only $36 \%$ of the patients suffering from psychological stress were willing to accept help for emotional or psychological difficulties. Instead, about $42 \%$ of the patients wanted support for their family (Baker-Glenn et al., 2011). Similarly, Merckaert et al. (2010) reported $26 \%$ (64\%) of Belgian women and $11 \%$ (15) of men expressing a desire for psychological support. A study by Dubruille et al. (2015) supported this finding; only $12 \%$ of older Belgian patients reported a desire for formal psychological help (Dubruille et al., 2015).

Only few studies have explored the expectations of patients with CRC towards their care, although they represent one of the most common cancer types globally (Forman et al., 2014). These patients may face a long-lasting CT phase with various treatment-related side effects; therefore, their care expectations may also be manifold and deserve to be comprehensively examined. This paper aimed to explore the expectations of patients with CRC towards their nursing care in the CT context. The results may be utilised to plan nursing interventions according to patients' expectations.

\section{Methods}

A descriptive qualitative research design was used to capture patients' expectations towards their care (Polit and Beck, 2017). The data were analysed using thematic analysis (Braun and Clarke, 2006; Vaismoradi et al., 2013). This study adhered to the COREQ guideline, which is relevant in reporting qualitative studies (Tong et al., 2007).

\subsection{Participants}

Purposive sampling was used to reach potential participants and provide rich data pertinent to the research question (Tong et al., 2007). Eligible participants were patients diagnosed with colon or rectal cancer, over 18 years, able to understand and speak Finnish, with ongoing or recently ended CT treatment in outpatient clinic. The university hospital was chosen, as it is responsible for CT treatment of 6000-7000 patients with CRC annually in a relatively large area in Finland with about 2 million population. Primary nurses in the CT unit approached the eligible participants and informed the researcher, who arranged the interviews according to the patients' schedule. Of the 19 patients recruited, 15 consented to participate in the study. Reasons for refusal were language or logistical difficulties.

\subsection{Interviews}

Data were collected with one-to-one interviews $(\mathrm{n}=15)$ between 20 Oct and Nov 27, 2017 by the first author (LT) working in the organisation as advanced practice nurse without direct involvement in patient care. Relationship between researcher and participants was not established prior to study commencement (Tong et al., 2007). A semistructured interview is a flexible method allowing free expression of thoughts without exact form or order. An interview guide with predetermined questions based on existing literature was used to focus the conversation on desired themes (Parahoo, 2014). The following questions were asked:

- What are your expectations towards nursing care during the treatment?

- What are your expectations for psychological care from the nurse during the treatment?

- What are your expectations for spiritual care from the nurse during the treatment?

- What are your expectations for social care from the nurse during the treatment?

- What are your expectations for knowledge from the nurse during the treatment?

- What are your expectations for concrete support from the nurse during the treatment?

The interview guide was tested during the first interview; no changes were made. The interviews lasted 18-86 min (mean $42 \mathrm{~min}$ ) and they were continued until new knowledge ceased to emerge (Holloway and Wheeler, 2010). Interviews were audio-recorded with participants' permission.

\subsection{Ethical considerations}

Ethical approval was obtained from the Research Ethics Committee of the Hospital District in June 2017 (HUS/1788/2017). Permission to conduct the study was obtained from the chief administrator of the Cancer Centre (HUS/238/2017). This work was carried out according to high ethical standards following the principles of the Declaration of Helsinki (World Medical Association, 2013). Eligible patients were informed both verbally and in writing. Anonymity, confidentiality and the voluntary nature of participation was highlighted. A nurse obtained written informed consent from each participant. Interviews were carried out in a private room to protect participants' right to privacy. At the beginning of the interview, the researcher explained her reasons for doing the research. Data files were stored in a password-protected computer, managed confidentially and discarded after analysis.

\subsection{Data analysis}

Thematic analysis was conducted using Braun and Clarke (2006) six phases. Transcribed texts were read thoroughly and preliminary notes were taken. Initial codes were generated and grouped meaningfully using separate computer files by the first author. The codes were sorted according to their content into potential themes using tables and thematic maps. Themes were identified at semantic level without 
interpretation. The authors discussed the preliminary themes, which were reviewed at the level of coded data extracts under each theme and in relation to the entire data set. At this point, some themes were collapsed and some others were formed. The themes were refined with accompanying narrative in order to find the essence of each theme. In the final analysis, the themes were named and analysis was reported (Braun and Clarke, 2006).

\section{Trustworthiness}

We use credibility, dependability and transferability to describe the trustworthiness in this study (Granaheim and Lundman, 2004). Credibility was supported by following systematically the guidelines of Braun and Clarke (2006) during the coding sessions and ensuring that all authors accepted the final themes (Elo and Kyngäs, 2008; Polit and Beck, 2017). The analysis was conducted at semantic level avoiding interpretation to make sure that the results correspond with the informants' experiences. The research question was constantly asked from the data to differentiate actual expectations from general experiences. The quotations in reporting confirm that themes have emerged from the participants' interviews and not from the mind of the researcher (Sutton and Austin, 2015). Participants' profound experience of the subject support credibility of the research (Granaheim et al., 2017). Rigorous literature search was conducted only after the data analysis to avoid the influence of previous research. The sample size was considered sufficient to reach the saturation. Dependability was supported by using the same interview guide for all participants (Polit and Beck, 2017) and by conducting the data collection and analysis over a relatively short period. The decision of transferability is left with the readers based on description of participants' characteristics (Table 1) (Granaheim and Lundman, 2004).

\section{Results}

The participants with colon or rectal cancer $(\mathrm{n}=15)$ included women $(\mathrm{n}=8)$ and men $(\mathrm{n}=7)$ aged $45-72$ years (medium 59.3$)$ suffering from either curable $(n=4)$ or advanced $(n=11)$ cancer. Patients were in various phases of CT treatment period.

Three main themes emerged from the data: Patients expected to be: (1) empowered with knowledge, (2) humanely encountered and (3) skillfully cared for (Fig. 1).

\subsection{Theme 1: Expectation of being empowered with knowledge}

This theme comprised three subthemes: expectation of having knowledge of disease process, knowledge of side effects and their self-

Table 1

Demographic data.

\begin{tabular}{lllllll}
\hline Participant & Gender & Age & Cancer type & Treatment type & $\begin{array}{l}\text { Stoma } \\
\text { Advanced } \\
\text { cancer }\end{array}$ \\
\hline P1 & male & 72 & colon & OP, CT & no & yes \\
P2 & male & 68 & rectum & OP, CT & yes & no \\
P3 & female & 45 & rectum & OP, CT & yes & yes \\
P4 & female & 72 & colon & OP, CT & no & yes \\
P5 & female & 53 & colon & OP, CT & no & yes \\
P6 & male & 66 & colon & OP, CT & no & yes \\
P7 & male & 56 & colon & OP, CT & no & yes \\
P8 & male & 55 & rectum & OP, CT, RT & yes & yes \\
P9 & male & 59 & rectum & OP, CT, RT & yes & no \\
P10 & female & 52 & colon & OP, CT & no & yes \\
P11 & female & 60 & colon & OP, CT & no & yes \\
P12 & female & 55 & colon & OP, CT & no & no \\
P13 & female & 71 & colon & OP, CT & no & yes \\
P14 & female & 56 & rectum & OP, CT, RT & yes & yes \\
P15 & male & 50 & rectum & OP, CT, RT & yes & no \\
& & & & & &
\end{tabular}

$\mathrm{OP}=$ operation, $\mathrm{CT}=$ chemotherapy, $\mathrm{RT}=$ radiation therapy. management, and knowledge of peer support.

Expectation of having knowledge of disease process entailed knowledge of the disease, treatment and care during the CT phase. The spreading and prognosis of cancer and having a general picture of the care path were emphasised. Expectation of knowing more about the justification for the decisions made related to treatment and care was common. Unawareness was typical especially in the case of advanced disease.

"I would have expected to know, why was it decided, all of a sudden, that they are not going to cure me anymore, but only trying to keep me alive?"(P7)

Two patients with advanced disease expected to know the reasons for waiting for a specific treatment or test. A sense of wasting time in queue and fear of disease progression while waiting was strong, thus a fixed date for treatment was desired instead of queuing.

"When you are transferred or somehow put on hold, it would be much easier if they gave you a date. You wouldn't have to be active and nasty or use elbow tactics because you knew the date." (P8)

Patients expected to have accurate knowledge of whether the CT was effective or not. Furthermore, some patients expected to have knowledge about different medication options, their effect mechanisms and reasons for a particular treatment.

"To have knowledge of how it effects, what drug effects cancer and what way ..." (P11)

In the case of advanced disease, patients reflected on the time remaining, expecting to have knowledge about care arrangements, and when necessary, adequate pain relief. Patients at the end of the CT phase expected to have knowledge of life after treatment to be prepared for the future.

"Probably they have a kind of form they follow, so I wish they gave it to patients, to let you know what's coming, a timetable a month before or so ..." (P15)

Knowledge of CT-induced side effects and their self-management was another common expectation. Sometimes dosage of medication or symptom self-monitoring seemed unclear for patients. Thus, they expected consistent and understandable information of self-care at home both orally and in writing. Patients were interested especially in the concrete manifestations of the side effects, such as coronary symptoms or circulatory disorders, as well as their individual appearance.

"In the beginning, you need explicit knowledge of the effect, what is to come, what it actually means when you get cold allergy, everything related to it. So maybe that's the biggest thing, the effect of those drugs." (P14)

Patients expected to have knowledge of how to anticipate the CT side effects. This included detailed instructions of how to be prepared for treatment, especially for persistence and intensity of neuropathic symptoms.

"I was surprised it was so hard, I wasn't prepared. It was so tough on the hands! It was new to me ... so, they could have told me that." (P2)

Furthermore, patients expected to have knowledge of nutrition and side effects such as reduced appetite, weight loss, nausea and cold allergy to secure nourishment and fluid intake during the treatment.

"I didn't really know anything about these food things. I used to be 50-52 kilos and now I'm 45, and it has been about three months. It would need some kind of food thing here." (P13)

In addition, patients expected to have knowledge of whether the side effects will be permanent.

"So you think all the time of the symptoms; what is this, is this going to be 


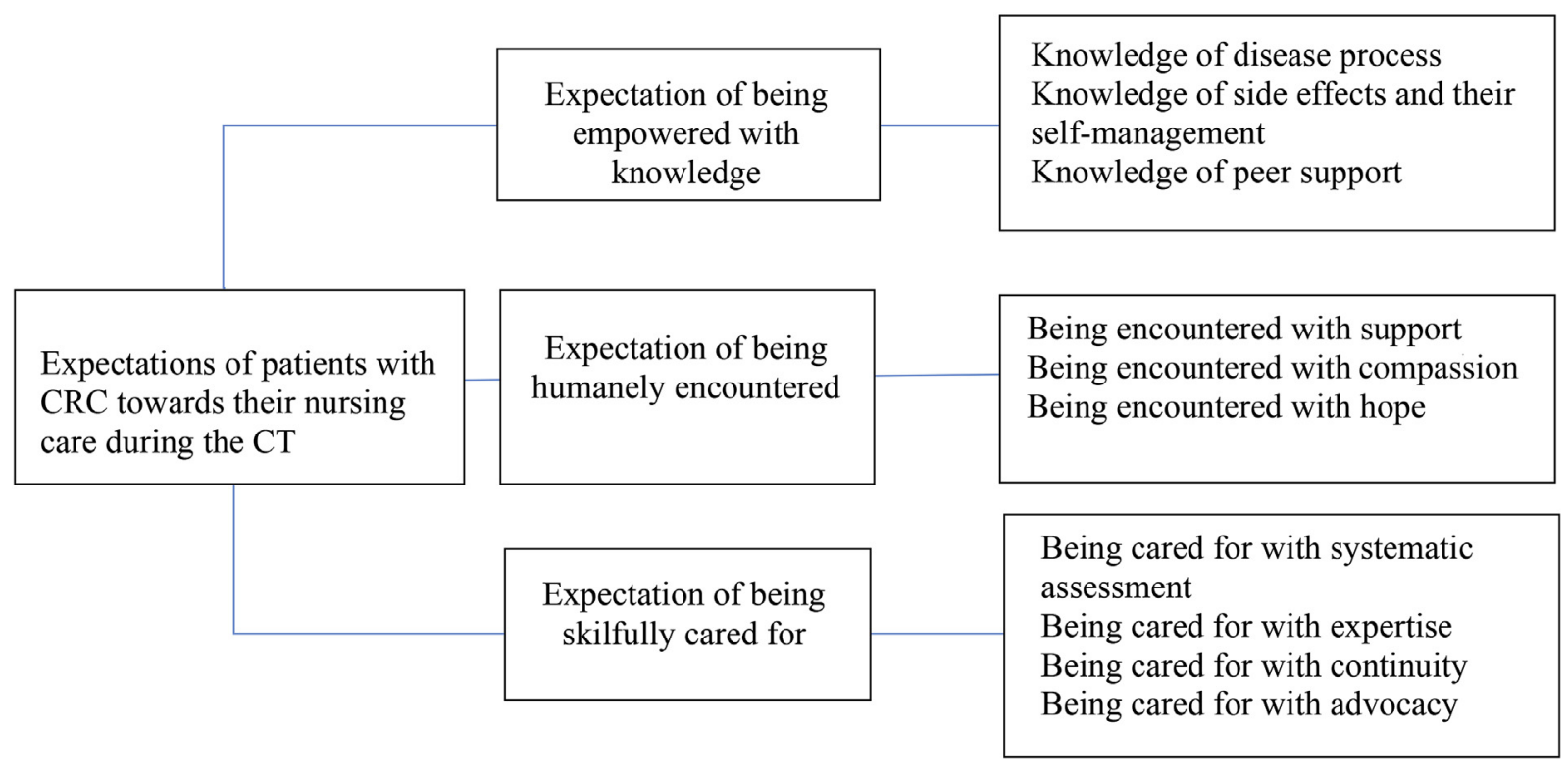

Fig. 1. Expectations of patients with CRC towards their nursing care during the chemotherapy.

permanent and chronic, will it get better next week." (P12)

Only few patients brought forward the expectation to have knowledge of possibilities to meet a sex therapist. This was perceived as a sensitive issue, which was not discussed with a primary nurse but postponed or referred to brochures in outpatient clinic.

Some patients with stoma expected to have another appointment with a nurse specialist to discuss the permanent life change. One patient expected to have knowledge of mood changes to inform close ones of the effects of the disease and its treatment on mood, such as touchiness and snappishness at home.

"I can tell you my nerves are tight, it really irritates, this ongoing ... unhappy feeling. Maybe it would be nice to have some kind of brochure for them ... like, try to hold on, she acts up, don't make a big deal of it ..." (P13)

Expectation of having knowledge of peer support from someone going through the same treatment was generally expressed, especially in connection with a large operation or spread disease.

"I wish to talk with someone who has the same situation. It makes me feel I'm not alone, I mean. That has the same kind of symptoms, and they may pass within a week or so. It makes it easier, somehow ..." (P12)

However, one patient expressed peer support being distressing when realising there might still be a long journey ahead. Some patients expected to have knowledge of peer support through cancer associations. One patient suggested their introduction for nurses, as well.

"There could be someone to introduce this association to nurses; professionals don't necessarily have the knowledge." (P8)

\subsection{Theme 2: Expectation of being encountered humanely}

This theme consisted of four subthemes: being encountered with support, with compassion and with hope.

Expectation of being encountered with support consisted of encouragement, which involved nurse being honest by facing the facts whilst being hopeful.

“... a kind of positive spurring, I expect that, there's vigorous, factual care, not too gentle or smooth-talking."(P4)

In addition, support actualised while nurse was acting as a backup when something out of the ordinary was happening, e.g. hair loss or follow-up examination.

"I expect support from the nurse. Today, as I left for home, she raised her thumb and said: I'll keep my fingers crossed for you for tomorrow's radiography results!" (P8)

In some case, positive briskness was perceived as one of the most important forms of support during the care.

"Of course, I expect this certain kind of joyfulness; that it's not so gloomy and sad business." (P1)

When a nurse was providing support by showing behaviours such as sympathy, empathy, honesty and providing hope, it gave a patient an inner peace, a fearless feeling and alleviation of anxiety. Talking to a nurse who is listening eased the burden of illness. Patients expected support for living in the moment, accepting what is to come and not worrying for the future. This appeared as accepting the treatments and taking one day at a time without thinking of tomorrow.

"I don't think this is the end, at least not yet, but you never know. It's no use worrying in advance. I wish to go on like there was nothing at all, as far as my condition allows me to." (P1)

Patients expected to be encountered with compassion, e.g. nurses being cheerful and friendly, making jokes, smiling and having a welcoming attitude. Patients expressed their expectations of compassion in various ways; for example, as nurse being nice, marvellous, sweet or lovely. In addition, patients highlighted their expectation of nurse being compassionate by referring to a nurse being 'a motherly type' or 'a good person' and genuinely interested in a patient. One patients expected care to be a service from human to human.

"I expect there is the right person in the right place. I think that's the most important thing." (P8)

Expectation of being encountered with hope included hope for healing from cancer, discovering a new drug and living a normal life. Hope of healing was a general expectation pronounced by patients with advanced disease. Hope manifested itself in conversations with a nurse or a doctor strengthening trust in the future. Sometimes, false hope was perceived as better than no hope at all. Hope appeared as a desire to cling to cancer survivors and see things in a positive light.

"Now we move on with these treatments and then there is the healing end, 
basically, it's been that way for me from the beginning ... I expect at some point this will be over." (P4)

Hope of discovering a new drug included desire for a new treatment method, which maintained the hope.

"Of course you keep hoping for a new treatment, you always read the news, hoping that you'll stay alive that long ..." (P7)

Patients emphasised expectation of hope of normal life in spite of cancer. Some patients hoped the side effects would not be a permanent part of life. This was expressed as being afraid of a miserable life but not death. One patient wished not to be labelled as a cancer patient and protected oneself from the identity of a person with cancer.

"Somehow, I don't want that identity for myself, being a patient with ileostomy or cancer ... but expect to live, not a normal life, but not as a cancer patient, not just outwards but inwards as well, a wish to protect oneself that way." (P14)

Hope of going back to work signified working as much as one is capable in a changed situation and being supported by healthcare workers. Expectation of continuing with an old hobby included having a normal life despite the ileostomy.

"I expect to be able to live a normal life, obviously. I'd like to exercise more, not to get out of shape, you know. Of course, I'm retired now, but don't prefer just lying down. I honestly hope to return to my winter swimming." (P2)

\subsection{Theme 3: Expectation of being skillfully cared for}

This subtheme included four subthemes: being cared for with systematic assessment, with expertise, with continuity, and with advocacy.

Patients expressed expectation of systematic assessment, which comprised expectation of holistic assessment of nursing care, life situation and coping with the disease at every turn of the care path. Patients expected to have a clear picture of what is behind and what is still ahead.

"When you arrive you should see a nurse to check how you have been, more generally, and what the mood has been at home." (P3)

A part of systematic assessment was a common expectation of having routine appointment of nutrition counselling and in some cases a social worker for financial support without asking.

"I felt so sick! In the beginning there could be planned nutrition consultation before the CT, a progression plan, and maybe revise it later on." (P10)

Expectation of being cared for with expertise pronounced in most patients' expectations. To be cared by skilled professionals inspired trust in patients, which was described as being 'in good hands', having nothing to worry about, and being able to surrender oneself to treatment.

"You are nervous about the treatment and all; on the other hand, you just surrender. It's like being on the plane, you know? You have to trust the captain. Otherwise the whole trip is ruined." (P14)

In addition, patients expected assistance during the treatment, which was described as nurses being available and ensuring everything was fine.

"I expect I'm not just left there, somehow they are there all the time, moving around and asking if everything is OK... I feel they take really good care of me." (P3)

Patients expected nurses to be calm, not making a fuss. This related to nurses seldom expressing their hurry despite having many patients to take care of.
"There is a peace when you are there, no fear. And you don't have to be stressed." (P9)

Patients expected to have straightforward conversations with a nurse even when dealing with sensitive themes. The nurse was expected to read the patient's emotional state and have time to listen. Often topics were related to private life, which was perceived as nurses doing 'more than just their work'.

"My expectations are shaped so that I get exact information related to treatments and care and then this small talk."(P7)

Being cared for with continuity indicated that the same nurse was expected to take care of the patient throughout the care. The nurse was perceived to know the individual nuances of the care, anticipate patients' needs and pass on the knowledge to other nurses if absent. Continuity manifested as being assisted between treatment cycles if needed by text message, telephone or e-mail.

“... if there's something troubling you, you have this calling hour. A couple of times I've called and got help, I expect that kind of good support." (P8)

Patients highlighted expectation of being cared for with advocacy. Nurses acted as intermediaries between doctor and patients, e.g. asking for additional instructions for symptom management.

"When I tell her of my sensations, I expect she knows the answer or else asks the doctor - I've received an answer every time." (P5)

Furthermore, patients expected to be cared for with the same intensity regardless of cancer type or personal background.

"Breast cancer patients had ice cubes and cooling caps and the window open, while the two of us in the same room were actually freezing, I expected someone keeping us warm, too ..." (P10)

\section{Discussion}

This study explored the expectations of patients with CRC for nursing care in the CT context. Thematic analysis revealed multifaceted, yet practicable expectations categorized into three main categories.

The first category, patients' expectation of being empowered with knowledge confirmed earlier research results (Goossens et al., 2014; Kotronoulas et al., 2017; Simacek et al., 2007; Tombal et al., 2013; Vaartio-Rajalin et al., 2014, 2015; van Weert et al., 2013). However, related to knowledge of their treatment and care, Finnish patients with CRC expected to be strictly aware of what is happening in their care and justifications for decisions made whereas majority of Greek patients with breast cancer have preferred to have passive role in decisionmaking (Almyroudi et al., 2011). In a study of Tombal et al., 2013, more than half of the patients with prostate cancer surveyed in four European countries stated preferring a collaborative approach to decision-making. In Italy and Spain, most of the patients left decisionmaking to their physician alone. Similarly, patients with cancer in Sweden, Finland and Cyprus rated the actualisation of their decisional control in the care high compared to the respondents in Greece (Suhonen et al., 2018). In Finland, the legislation protecting patients' rights for good health care, knowledge and self-determination (Ministry of Social Affairs and Health, 1992), high education (Suhonen et al., 2018; Official Statistics of Finland, 2019) and active use of Internet (89\%) (Official Statistics of Finland, 2018) might be influencing factors to patients' more active role and high expectations for health related knowledge. Patients' expectations for the knowledge of the individual nature of the side effects was pronounced in our data. Similarly, patients with CRC have expected tailored information after surgery (Beaver et al., 2010). However, there has been shortcomings in the actualisation of personally tailored care responding to the specific needs of patients diagnosed with cancer (Suhonen et al., 2018). In 
previous studies, patients' knowledge expectations have been high but the level of received knowledge has not corresponded to expectations (Klemetti et al., 2015). Therefore, the assessment of patients' knowledge needs is important in clinical practice to support self-care of patients with cancer.

In this study, patients considered it was important to have knowledge of peer support possibilities. Recent research by Kanters et al. (2018) has shown favourable effects of peer support among patients with CRC on attitudes and adherence to CT. The authors conclude that facilitated peer support programs could positively influence patient expectations and coping with diagnosis and treatment. Therefore, peer support arranged in the outpatient clinic either during the treatment or at some other convenient time might be beneficial for these patients.

The second category, patients' expectation of being encountered humanely actualised when a nurse was providing support by showing behaviours such as compassion, being honest and maintaining hope. Expectations of patients with CRC towards a nurses' behaviour did not emerge in our search of literature. According to McCormack and McCance (2017), the way nurses are sympathetically present and available to each patient in the moment reflects the quality of nursepatient relationship. Earlier research suggests that respect for patients in nurses' "being with" and "doing for" plays a crucial role in older patients' assessments of their care satisfaction (Koskenniemi et al., 2019). Thus, it is important to practice these behaviours during the clinical practicum and maintain them in clinical work through continuous education. Kotronoulas et al. (2017) found that the most prominent need for emotional support was related to fear of cancer recurrence among patients with CRC; however, this was not the case in our study. Patients rather lived in the moment without worrying for the future. Salander et al. (2014) detected different mental manoeuvres to create hope among patients with lung cancer $(n=15)$. Authors assumed that by distancing oneself mentally from the disease or maintaining a positive attitude is a method to create hope. It might be the same in this study; however, it requires further research.

In this study, most of the patients seemed to receive sufficient support through the relationship with a nurse. It is interesting to note that patients were neither expecting a referral to psychological care nor expressing expectations of spiritual support from the nurse. However, this does not mean that these expectations do not exist. Spiritual needs are proved common although seldom asked among cancer population (Astrow et al., 2018). One patient perceived positive briskness of a nurse being one of the most important forms of support during the care. It may be concluded that when expectations of being encountered humanely are met in patient-nurse relationship there is less need for professional psychological support. However, further research is necessary to identify the characteristics or behaviour of a nurse that makes patients feel they are humanely encountered. As a relationship based on kindness is a starting point for respecting personhood in health care encounters (McCormack and McCance, 2017), there is clearly a need to foster a genuine and sustainable patient-nurse relationship in clinical practice.

The third category, patients' expectation of being skillfully cared for highlighted the importance of a systematic assessment of care. This entails a holistic assessment of patients' life situation and supporting patients' empowerment. The expectation is understandable as care needs may change (Ryhänen et al., 2012; Thorne et al., 2014) during the potentially long-lasting CT phase and an important aspect to consider in nursing practice. As a self-evident fact, patients expected to be able to trust in the professional skills of a nurse who delivers the care. In light of our findings, it seems that the relationship between a patient and primary nurse is a perceptible embodiment of trust. According to Dinc and Gastmans (2013), the development of trust is related to the professional competence and interpersonal caring attributes of nurses as human beings. McCormack and McCance (2017) have outlined that nurses being professionally competent is one of the prerequisites for person-centred care. In this study, patients' expectation of continuity in care (see also Beaver et al., 2010; Kotronoulas et al., 2017) actualised in a relationship with a nurse. Results showed that nurses are in a significant role to advocate patients' care needs forward. This finding is supported in a study of Vaartio-Rajalin and Leino-Kilpi (2011), where nurses responded to the clinical and ethical needs of patients with cancer by representing their needs; for example, of symptom management, development of treatment plan and initiating discussion with physicians. In these situations, nurses were acting as a mediating third party in the dialogue, representing the patient and his or her preferences. This role is emphasised in the CT context as patients may come face-to-face with a physician only a few times.

Limitation of this study is that interviews lasted relatively short period (mean $42 \mathrm{~min}$ ), however; rich data was obtained during these sessions. Furthermore, nurses were recruiting the participants, which may have led to selective choice, although inclusion criteria were clear. Finally, the findings are limited to expectations of patients with CRC during the CT treatment. Because expectations vary during the care, future research should study expectations of these patients during various phases of illness and forms of care.

\section{Conclusion}

Patients' expectations appeared to be multifaceted. The expectation of individual and empowering knowledge strengthened the previous research results. Patients' expectations of being humanely encountered revealed expectations towards a nurses' behaviour that may help patients to be empowered in their complicated situation with illness. To meet patients' expectations of skilful care it is important to foster the evidence-based practice and the sustainability of a patient-nurse relationship. The results of this study may help nurses to provide patientcentred care according to their expectations. Moreover, the results may be utilised in further education of nurses by focusing themes significant to this patient group. In the future, researchers should develop nursing interventions that take into account patients' expectations in their care.

\section{Declaration of competing interest}

None declared.

\section{References}

Almyroudi, A., Degner, L.F., Paika, V., Pavlidis, N., Hyphantis, T., 2011. Decision-making preferences and information needs among Greek breast cancer patients. Psycho Oncol. 20, 871-879. https://doi.org/10.1002/pon.1798.

Astrow, A., Kwok, G., Sharma, R., Fromer, N., Sulmasy, D., 2018. Spiritual needs and perception of quality of care and satisfaction with care in hematology/medical oncology patients: a multicultural assessment. J. Pain Symptom Manag. 55, 56-64. https://doi.org/10.1016/j.jpainsymman.2017.08.009.

Baker-Glenn, E., Park, B., Granger, L., Symonds, P., Mitchell, A., 2011. Desire for psychological support in cancer patients with depression or distress: validation of a simple help question. Psycho Oncol. 20, 525-531. https://doi.org/10.1002/pon. 1759.

Beaver, K., Latif, S., Williamson, S., Procter, D., Sheridan, J., Heath, J., et al., 2010. An exploratory study of the follow-up care needs of patients treated for colorectal cancer. J. Clin. Nurs. 19, 3291-3300. https://doi:10.1111/j.1365-2702.2010.03407.x.

Braun, V., Clarke, V., 2006. Using thematic analysis in psychology. Qual. Res. Psychol. 3, 77-101. https://doi.org/10.1191/1478088706qp063oa.

Bray, F., Ferlay, J., Soerjomataram, I., Siegel, R., Torre, L., Jemal, A., 2018. Global Cancer Statistics 2018: GLOBOCAN estimates of incidence and mortality worldwide for 36 cancers in 185 countries. CA Cancer J. Clin. 68, 394-424.

Dinc, L., Gastmans, C., 2013. Trust in nurse-patient relationships: a literature review. Nurs. Ethics 20, 501-516. https://doi.org/10.1177/0969733012468463.

Dubruille, S., Libert, Y., Merckaert, I., Reynaert, C., Vandenbossche, S., Roos, M., et al., 2015. The prevalence and implications of elderly inpatients' desire for a formal psychological help at the start of cancer treatment. Psycho Oncol. 24, 294-301. https://doi.org/10.1002/pon.3636.

Elo, S., Kyngäs, H., 2008. The qualitative content analysis process. J. Adv. Nurs. 62 107-115. https://doi.org/10.1111/j.1365-2648.2007.04569.x.

Forman, D., Ferlay, J., Stewart, B., Wild, C., 2014. The global and regional burden of cancer. In: Stewart, B.W., Wild, C.P. (Eds.), World Cancer Report. International Agency for Research on Cancer, Lyon, pp. 16-53. http://publications.iarc.fr/NonSeries-Publications/World-Cancer-Reports/World-Cancer-Report-2014, Accessed date: 15 January 2018 
Granaheim, U.H., Lundman, B., 2004. Qualitative content analysis in nursing research: concepts, procedures and measures to achieve trustworthiness. Nurse Educ. Today 24, 105-112. https://doi.org/10.1016/j.nedt.2003.10.001.

Granaheim, U.H., Lindgren, B.-M., Lundman, B., 2017. Methodological challenges in qualitative content analysis: a discussion paper. Nurse Educ. Today 56, 29-34. https://doi.org/10.1016/j.nedt.2017.06.002.

Halkett, G., Kristjanson, L., Lobb, E., Little, J., Shaw, T., Taylor, M., et al., 2012. Information needs and preferences of women as they proceed through radiotherapy for breast cancer. Patient Educ. Couns. 86, 396-404. https://doi:10.1016/j.pec.2011. 05.010.

Health Innovation Network, 2016. What Is Person-Centred Care and Why Is it Important? Updated July 18 2016. https://healthinnovationnetwork.com/system/ckeditor assets/attachments/41/what_is_person-centred_care_and_why_is_it_important.pdf, Accessed date: 20 October 2018.

Holloway, I., Wheeler, S., 2010. Qualitative Research in Nursing Health Care, third ed. Wiley- Blackwell, United Kingdom.

Kanters, A., Morris, A., Abrahamse, P., Suwanabol, P., 2018. The effect of peer support on colorectal cancer patients' adherence to guideline-concordant multidisciplinary care. Dis. Colon Rectum 61, 817-823.

Klemetti, S., Leino-Kilpi, H., Cabrera, E., Copanitsanou, P., Ingadottir, B., Istomina, N., et al., 2015. Difference between received and expected knowledge of patients undergoing knee or hip replacement in seven European countries. Clin. Nurs. Res. 24, 624-643. https://doi.org/10.1177/1054773814549992.

Koskenniemi, J., Leino-Kilpi, H., Puukka, P., Suhonen, R., 2019. Respect and its associated factors as perceived by older patients. J. Clin. Nurs. 28, 3848-3857. https:// doi.org/10.1111/jocn.15013.

Kotronoulas, G., Papadopoulou, C., Burns-Cunningham, K., Maguire, R., 2017. A systematic review of the supportive care needs of people living with and beyond cancer of the colon and/or rectum. Eur. J. Oncol. Nurs. 29, 60-70.

Kvåle, K., Bondevik, M., 2008. What is important for patient centred care? A qualitative study about the perceptions of patients with cancer. Scand. J. Caring Sci. 22, 582-589. https://doi.org/10.1111/j.1471-6712.2007.00579.x.

McCormack, B., McCance, T., 2017. Person-centred Practice in Nursing and Health Care. Theory and Practice, second ed. Wiley Blackwell, United Kingdom.

Merckaert, I., Libert, Y., Messin, S., Milani, M., Slachmuylder, J.L., Razavi, D., 2010. Cancer patients' desire for psychological support: prevalence and implications for screening patients' psychological needs. Psycho Oncol. 19, 141-149. https://doi.org/ 10.1002/pon.1568

Ministry of Social Affairs and Health, 1992. Act on the Status and Rights of Patients 785/ 1992. Finland, Helsinki August 1992. https://www.finlex.fi/fi/laki/kaannokset/ 1992/en19920785 20120690.pdf, Accessed date: 20 October 2019.

Morgan, S., Yoder, L.H., 2012. A concept analysis of person-centred care. J. Holist. Nurs. 30, 6-15. https://doi.org/10.1177/0898010111412189.

Official Statistics of Finland (OSF), 2018. Use of Information and Communications Technology by Individuals. December 2018. Helsinki. https://www.stat.fi/til/sutivi/ 2018/sutivi_2018_2018-12-04_tie_001_en.html, Accessed date: 20 October 2019.

Official Statistics of Finland (OSF), 2019. Educational Structure of Population. Helsinki. https://www.stat.fi/til/vkour/index en.html, Accessed date: 20 October 2019.

Parahoo, K., 2014. Nursing Research. Principles, Process and Issues, third ed. Red Globe Press, United Kingdom.

Pardon, K., Deschepper, R., van der Stichele, R., Bernheim, J., Mortier, F., Deliens, L., 2009. Preferences of advanced lung cancer patients for patient-centred information and decision-making: a prospective multicentre study in 13 hospitals in Belgium. Patient Educ. Couns. 77, 421-429. https://doi:10.1016/j.pec.2009.09.011.

Polit, D., Beck, C., 2017. Nursing Research: Generating and Assessing Evidence for Nursing Practice, tenth ed. Wolters Kluwer Health, United States.

Rasmusson, E.-M., Plantin, L., Elmerstig, E., 2013. Did they think I would understand all that on my own? A questionnaire study about sexuality with Swedish cancer patients. Eur. J. Cancer Care 22, 361-369. https://doi.org/10.1111/ecc.12039.

Roberts, K., Lepore, S., Urken, M., 2008. Quality of life after thyroid cancer: an assessmen of patient needs and preferences for information and support. J. Cancer Educ. 23, 186-191. https://doi.org/10.1080/08858190802247762.

Ryhänen, A.M., Rankinen, S., Siekkinen, M., Saarinen, M., Korvenranta, H., Leino-Kilpi, H., 2012. The impact of an empowering Internet-based Breast Cancer Patient Pathway programme on breast cancer patients' knowledge: a randomised control trial. Patient Educ. Couns. 88, 224-231. https://doi.org/10.1016/j.pec.2012.02.013.

Salander, P., Bergknut, M., Henriksson, R., 2014. The creation of hope in patients with lung cancer. Acta Oncol. 53, 1205-1211. https://doi.org/10.3109/0284186X.2014. 921725.

Shun, S.-C., Yeh, K.H., Liang, J.T., Huang, J., Chen, S.-C., Lin, B.R., et al., 2014. Unmet supportive care needs of patients with colorectal cancer: significant differences by type D personality. Oncol. Nurs. Forum 41, E3-E11. https://doi:10.1188/14.ONF.E3 E11.

Simacek, K., Raja, P., Chiauzzi, E., Eek, D., Halling, K., 2007. What do ovarian cancer patients expect from treatment? Perspectives from an online patient community. Cancer Nurs. 40, 17-26. https://doi:10.1097/NCC.0000000000000415.

Suhonen, R., Charalambous, A., Berg, A., Katajisto, J., Lemonidou, C., Patiraki, E., et al., 2018. Hospitalised cancer patients' perceptions of individualized nursing care in four European countries. Eur. J. Cancer Care 27, e12525. https://doi.org/10.1111/ecc. 12525.

Sutton, J., Austin, Z., 2015. Qualitative research: data collection, analysis, and management. Can. J. Hosp. Pharm. 68, 226-231. http://www.cjhp-online.ca/index.php/ cjhp.

Thorne, S., Hislop, G., Kim-Sing, C., Oglov, V., Oliffe, J., Stajduhar, K., 2014. Changing communication needs and preferences across the cancer care trajectory: insights from the patient perspective. Support. Care Cancer 22, 1009-1015. https://doi:10.1007/ s00520-013-2056-4.

Tombal, B., Baskin-Bey, E., Schulman, C., 2013. Access to information and expectations of treatment decisions for prostate cancer patients - results of a European survey. Eur. J. Cancer Care 22, 210-218. https://doi.org/10.1111/ecc.12020.

Tong, A., Sainsbury, P., Craig, J., 2007. Consolidated criteria for reporting qualitative research (COREQ): a 32-item checklist for interviews and focus groups. Int. J. Qual. Health Care 19, 349-357. https://doi.org/10.1093/intqhc/mzm042.

Vaartio-Rajalin, H., Leino-Kilpi, H., 2011. Nurses as patient advocates in oncology care: activiteis based on literature. Clin. J. Oncol. Nurs. 15 (5), 526-532. https://doi.org/ 10.1188/11.CJON.526-532.

Vaartio-Rajalin, H., Leino-Kilpi, H., Iire, L., Lehtonen, K., Heikki, M., 2015. Oncologic patients' knowledge expectations and cognitive capacities during illness trajectory. Holist. Nurs. Pract. 29, 232-244. https://doi:10.1097/HNP.0000000000000093.

Vaartio-Rajalin, H., Leino-Kilpi, H., Puukka, P., 2014. Exploring patients' knowledge expectaitons during the illness trajectory. Cancer Nurs. Pract. 13 (4), 30-38. https:// doi.org/10.7748/cnp2014.05.13.4.30.e1054.

Vaismoradi, M., Turunen, H., Bondas, T., 2013. Content analysis and thematic analysis: implications for conducting a qualitative descriptive study. Nurs. Health Sci. 15, 398-405, https://doi.org/10.1111/nhs.12048.

van Weert, J., Bolle, S., van Dulmen, S., Jansen, J., 2013. Older cancer patients' information and communication needs: what they want is what they get? Patient Educ. Couns. 92, 388-397. https://doi.org/10.1016/j.pec.2013.03.011.

World Medical Association, 2013. Declaration of Helsinki - Ethical Principles for Medical Research Involving Human Subjects. 64th WMA General Assembly, Fortaleza, Brazil, October 2013. https://www.wma.net/policies-post/wma-declaration-of-helsinkiethical-principles-for-medical-research-involving-human-subjects/, Accessed date: 19 October 2018. 